\title{
ANÁLISE DISCURSIVA DO PROGRAMA ACADEMIA DA CIDADE DE BELO HORIZONTE/MG ${ }^{1}$
}

Recebido em: 23/12/2014

Aceito em: 06/12/2015

Marcos Gonçalves Maciel $^{2}$

Leonardo Antônio Soares ${ }^{3}$

Universidade do Estado de Minas Gerais/Unidade Ibirité

Ibirité - MG - Brasil

RESUMO: A atividade física praticada no tempo livre ou como lazer, tradicionalmente é utilizada como meio profilático. Assim sendo, este trabalho tem como objetivo analisar o conteúdo do programa Academia da Cidade em Belo Horizonte/MG. Adotamos como base teórica a Análise Crítica do Discurso proposta por Fairclough, pelo fato de ser considerada uma teoria potencial para o entendimento das relações de poder e das ideologias frequentemente presentes no discurso. $\mathrm{O}$ texto analisado apresenta um discurso de que a prefeitura cumpre a sua responsabilidade social ao oferecer a prática de atividade física orientada e gratuita à população. A prática social discutida nesse discurso é o da atividade física como fator de promoção da saúde e qualidade de vida, mas com o intuito de se prevenir as doenças crônicas não transmissíveis, o que denota uma perspectiva funcionalista para essas atividades e, não como meio de lazer crítico e criativo.

PALAVRAS CHAVE: Atividades de Lazer. Atividade Motora. Saude.

\section{DISCURSIVE ANALYSIS OF THE PROGRAM "CITY OF BELO HORIZONTE GYM/MG"}

ABSTRACT: This paper aims to analyze the discourse presented in the City Academy Program in Belo Horizonte/MG. In order to achieve the aims, we adopted as the theoretical basis the Critical Discourse Analysis proposed by Fairclough, because it is considered a potential theory to the understanding of power relations and ideologies often present in the discourse. The analyzed text presents a speech that the city fulfills its social responsibility towards the population by offering physical activity oriented and free to the population. The social practice presented through the discourse is the one of the physical activity as health promotion and quality of life factor, but in order to prevent chronic diseases, which denotes a functionalist perspective to these activities.

\footnotetext{
${ }^{1}$ Marcos G. Maciel recebe bolsa de estudo para o doutorado da Fundação de Amparo a Pesquisa do Estado de Minas Gerais (FAPEMIG - PCRH 90402/14).

${ }^{2}$ Professor do curso de Educação Física. Mestre e Doutorando em Estudos do Lazer - EEFFTO -UFMG. Graduado em Educação Física - EEFFTO-UFMG.

${ }^{3}$ Docente do curso de Letras da Universidade do Estado de Minas Gerais, Unidade Ibirité. Doutor em Linguística Aplicada e Estudos da Linguagem pela PUC-SP. Mestre em Estudos Linguísticos e Especialista em Ensino de Língua Inglesa pela UFMG.
} 
KEYWORDS: Leisure Activities. Motor Activity. Health.

\section{Introdução}

O reconhecimento do lazer enquanto direito social em nosso país, tem sido desenvolvido com mais propriedade nos últimos anos. O poder público tem implementado projetos sociais que visam a garantia de tais direitos ao cidadão, como um bem público, democrático e de acesso universal (FLAUSINO; MASCARENHAS, 2012; ANDRADE, 2008). Todavia, embora reconhecido esse avanço, ainda se faz necessário maiores investimentos, sejam na esfera política, econômica e educacional, para promover sua efetivação para a grande parcela da população.

O desenvolvimento da área tem sido tratado em diversos debates acadêmicos e governamentais. Essa ampla discussão vem possibilitando a elaboração de propostas de intervenções, de forma a buscar uma possibilidade concreta de atingir o status de direito social (MARCELLINO, et al., 2007; SUASSUNA; AZEVEDO, 2007).

No entanto, a elaboração e efetivação dessas políticas sociais, deveriam considerar alguns aspectos, como a concepção de lazer dos gestores, normalmente pautada pela perspectiva funcionalista e reducionista - atrelada ao descanso e entretenimento; a formação dos agentes; a intersetorialidade das ações (AREIAS; BORGES, 2011).

Fruto dessas políticas, nos últimos anos, percebe-se, o crescente o número de projetos sociais para promover a prática da atividade física em todo o país (MACIEL; DIAS; SILVA, 2014). Os mesmos têm como objetivo principal a promoção da saúde por meio da adoção de um estilo de vida saudável, sobretudo, incentivando a prática dessa atividade. 
O Programa Academia da Cidade de Belo Horizonte segue essa perspectiva. Contudo, percebe-se por parte do governo, uma transferência para a pessoa a responsabilidade de ser fisicamente ativa e saudável, através de um discurso de culpabilização do mesmo (CARVALHO, 2005), desconsiderando fatores determinantes, tais como: infraestrutura sanitária, emprego/renda, moradia, escolarização, atendimento médico, dentre outros.

Sendo assim, este trabalho tem como objetivo analisar o conteúdo desse programa disponibilizado no portal da prefeitura de Belo Horizonte/ $\mathrm{MG}^{4}$. Para tanto, adotamos como base teórica a Análise Crítica do Discurso - ACD -, proposta por Fairclough $(1994 ; 1995 ; 2001)$, pelo fato dela ser considerada uma teoria potencial para o entendimento das relações de poder e das ideologias frequentemente presentes no discurso.

Segundo Rodrigues Junior (2009) a ACD apresenta um conjunto de fatores de análise que procura desvelar relações injustas de poder e construções ideológicas ocultas nos discursos produzidos, sobretudo pela mídia, fato que mostra claramente sua importância na compreensão do processo dialético que permeia essas relações. Considerando essas características pretendemos compreender a mensagem do discurso ideológico que esse programa apresenta à população.

Para Fairclough (1994) conceituar “discurso" é uma tarefa bastante complexa por haver tantas definições conflitantes formuladas por diferentes áreas. Segundo ele, é mais comum, em linguística, o "discurso" se referir à linguagem escrita ou falada. O discurso enfatiza a interação entre o falante e o ouvinte; ou entre escritor e leitor e, sendo assim, um processo de produção, interpretação e uso da língua em determinados

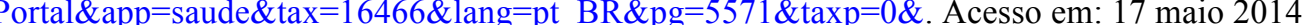


contextos situacionais. Outro ponto importante na concepção de Fairclough e da ACD é o foco dado na mudança histórica, ou seja, como os diferentes discursos são combinados sob condições sociais particulares para formar um novo e complexo discurso.

Soares (2011) busca analisar o discurso frente às mudanças que têm ocorrido no mercado de consumo globalizado e, consequentemente, nas diferentes áreas da vida social. Tais mudanças afetam as relações sociais e as identidades das pessoas e parte delas consiste em mudanças nas práticas discursivas, ou seja, no uso da língua e como ele tem assumido grande importância como um meio de produção e controle social. Assim, na concepção de Fairclough, estamos testemunhando um "tecnologização" do discurso, onde as tecnologias discursivas estão sendo sistematicamente aplicadas em uma série de organizações por pessoas que pesquisam, redesenham e fornecem treinamento nas práticas discursivas. Práticas discursivas, que tradicionalmente pertenciam à esfera particular, estão sendo sistematicamente simuladas dentro de organizações.

Fairclough (2001) apresenta a sua concepção tridimensional do discurso que, segundo ele, é uma tentativa de unir as três tradições analíticas, indispensáveis para a análise do discurso.

Ao focar o discurso enquanto texto, Fairclough recorre a certas palavras e ao seu significado político e ideológico; como as palavras podem ser moldadas a partir de certos contextos e como elas estão relacionadas a fatores políticos e ideológicos. A prática discursiva envolve os processos de produção, distribuição e consumo de textos, sendo que a natureza destes processos varia de acordo com os diferentes tipos de discurso e fatores sociais. Já o discurso enquanto prática social se relaciona com os 
aspectos ideológicos e hegemônicos nele contidos e tais aspectos representam eixos norteadores para a análise de Fairclough. A concepção tridimensional de Fairclough se mostra essencial para a análise de nosso texto, pois partiremos da certas palavras e sua conotação ideológica, social e politica; passaremos pelo contexto social imediato de produção e difusão do discurso até chegarmos ao contexto social mais amplo (prática social).

\section{Resultados e Discussão}

A atividade física enquanto componente cultural vivenciada através dos séculos é influenciada pelos aspectos mítico-religiosos, pelas concepções eugênicas e higienista, e atualmente pelo apelo mercantil, o que gerou o fenômeno do culto ao corpo principalmente a partir do século passado. Como decorrência desses acontecimentos, criou-se um discurso com novos valores e normas no imaginário da sociedade ocidental. Fato esse que influenciou a formação de uma perspectiva reducionista da relação entre a saúde e atividade física. Esta passou a se constituir, principalmente, enquanto a movimentos tecnicamente aprendidos, focados na instrumentalização para o bem-estar pessoal e coletivo, sendo vivenciado no tempo livre. Esse viés teve como respaldo as premissas do risco epidemiológico advindo da Saúde Pública.

As diretrizes apresentadas por essa área para a proliferação dessas práticas, é que nos últimos 40 anos tem ocorrido uma alteração da tendência mundial em relação às características populacionais, influenciando diretamente a saúde tanto individual quanto coletivamente, que são as transições demográfica, epidemiológica e nutricional 
(MALTA et al., 2009; HALLAL; KNUTH, 2011) ${ }^{5}$. Esse cenário levou a Organização Mundial da Saúde (OMS) a elaborar a "Estratégia Global para Alimentação Saudável, Atividade Física e Saúde” (2004). Esse documento dedicou uma ênfase quanto à premência do estímulo à incorporação da prática da atividade física regular no estilo de vida das pessoas, para reduzir a incidência das doenças crônicas não transmissíveis (DCNT) ${ }^{6}$. Essa proposta é discutida por Hallal e Knuth (2011, p.182), quando alegam que:

O conjunto dessas transições, que vem modificando os perfis de morbimortalidade, acaba colocando a atividade física na lista de prioridades da agenda de saúde pública nacional e internacional, visto que a atividade física está relacionada de forma causal com a ocorrência de diversas doenças e agravos não-transmissíveis.

Contudo, há posicionamentos divergentes a essa proposta. É inegável a relevância social da atividade física enquanto componente cultural realizada, sobretudo, no tempo livre ou como lazer. Para Isayama (2007) a atividade física é uma das possibilidades de lazer mais difundida em nosso meio, tanto no que concerne à vivência quanto à assistência de jogos, bem como em competições esportivas. Todavia, Pimentel (2012) discorre sobre o discurso do "lazer ativo", pautado na perspectiva hegemônica biomédica, caracterizada pelo positivismo e funcionalismo, que preconiza a adoção de um estilo de vida fisicamente ativo. $\mathrm{O}$ autor destaca a necessidade de se pensar essa

\footnotetext{
5 Demográfica - declínio da taxa de fertilidade e de mortalidade, alterando a estrutura etária da população; Epidemiológica - mudança nos padrões de adoecimento e mortalidade, marcada pela redução de situação vinculadas às doenças infecciosas; Nutricional - nos países de renda alta significou basicamente uma mudança da desnutrição para a obesidade como o principal problema nutricional.

${ }^{6}$ Das 57 milhões de mortes no mundo em 2008, 36 milhões - ou 63,0\% - aconteceram em razão das DCNT, com destaque para as doenças do aparelho circulatório, diabetes, câncer e doença respiratória crônica. Cerca de $80,0 \%$ das mortes por DCNT ocorrem em países de baixa ou média renda, onde $29,0 \%$ das pessoas têm menos de 60 anos de idade. Nos países de renda alta, apenas 13,0\% são mortes precoces. No Brasil, como nos outros países, as doenças crônicas não transmissíveis constituem o problema de saúde de maior magnitude. São responsáveis por $72,0 \%$ das causas de óbitos (...) (MALTA; MORAIS NETO; SILVA JUNIOR, p. 426, 2011).
} 
proposta, em detrimento de uma prática mais crítica e respeitando as singularidades tanto pessoais, quanto sociais.

Concordamos com o pensamento de Pimentel e, entendemos que essas práticas superam a mera perspectiva funcionalista, também apontada por Marcellino (1987), ou como meio de reduzir as mazelas sociais ou como "remédio" (ISAYAMA, 2007). Importante é destacar que essas práticas, também, não devem ser encaradas como prioritárias em relação às outras experiências de lazer no tempo livre (CARVALHO, 2003; PALMA, 2001).

Ademais, é preciso superar a visão acrítica da atividade física realizada no tempo livre como sendo necessariamente de lazer - Marcellino (1987) destaca a necessidade de se observar os aspectos tempo e atitude, isto é, a subjetividade de cada pessoa ao vivenciar uma atividade para se classificar como sendo de lazer; e, igualmente, associála como causa linear de promoção de saúde, como apontado por Bacheladenski e Matiello Júnior (2010, p. 2569):

Nos estudos do lazer para a promoção da saúde, ainda predomina a lógica da ocupação ativa do corpo no tempo de não-trabalho (lazer ativo), revelando a influência do pensamento funcionalista, o qual, ao reduzir os vínculos entre sociedade e processo saúde-doença, indiscutivelmente não condiz com o propósito de promover a saúde da população.

O discurso casuístico entre atividade física no tempo livre e saúde, também é questionado por Albino; Hammes e Vaz (2011), ao apontarem a influência da indústria cultural na concepção de uma mentalidade e um apelo à construção imagética de um "corpo sarado" e saudável. Esses autores chamam a atenção quanto ao caráter da obrigatoriedade e de instrumentalização do ideário do bem-estar, como vida plena, para normalização dos corpos e das condutas. 
Tendo em vista esse posicionamento, ao analisarmos o discurso ideológico do Programa Academia da Cidade de Belo Horizonte, nos deparamos com várias dessas características anteriormente descritas.

A começar pelo título do link do programa na Website, já é claro o grande apelo à adesão ao mesmo pelo viés da "saúde". Este é um substantivo feminino, denotando um bom estado orgânico, sobretudo, se relacionando aos aspectos fisiológicos, contrapondo-se à doença e relacionando-se ao fato de ser sadio, robusto, forte.

As discussões sobre o conceito que envolve o tema saúde têm sido uma tônica desde a modernidade, notadamente a partir do século XVII quando o pensamento positivista passou a incorporar-se à Ciência. Segundo Farinatti e Ferreira (2006), o desenvolvimento das ciências naturais permitiu traçar um novo paradigma sobre a relação saúde-doença, em que as causas das morbimortalidades, passaram a ser atribuídas às condições sanitárias precárias dos centros urbanos em crescimento e não à casualidade ou castigos dos deuses ou de Deus.

A concepção biomédica da saúde desde o início do pensamento epidemiológico positivista era entendida simplesmente como a ausência de doença, representando assim, um reducionismo médico que considerava somente os sintomas patológicos das enfermidades para caracterizá-las.

Tomando como base essa concepção, Guedes (2004) relata que pelo fato da pessoa não estar apresentando sintomas de alguma doença, não quer dizer que esteja saudável, pois alguns sintomas de determinadas enfermidades só aparecem em seus estágios mais avançados, estando, portanto, “invisíveis” em vários momentos, como, por exemplo, a hipertensão arterial, o câncer, a diabetes etc.. Ainda segundo esse autor: 
afastar ao máximo os comportamentos de risco que possam precipitar o surgimento e o desenvolvimento das doenças (GUEDES, 2004, p.95).

Segundo Farinatti e Ferreira (2006) pode-se então compreender que a saúde precisa ser vista de forma sistêmica ou holística, havendo um equilíbrio que envolve as diversas dimensões do ser humano, ou seja, uma inter-relação dos diferentes aspectos de bem-estar biopsicossocial ${ }^{7}$ e não apenas uma perspectiva reducionista como apresentada pela OMS. Essa instituição conceituou saúde como um "estado completo de bem-estar físico, mental e social e não somente a ausência de doença ou enfermidade". A esse respeito, questiona-se se a saúde de uma pessoa pode ser classificada de maneira tão simplista? Segundo Serge e Ferraz (1997) essa concepção é ultrapassada e inadequada, primeiramente, por visar a uma perfeição inatingível, atentando-se as próprias características da personalidade, bem como por apresentar uma definição irreal por que, aludindo ao "perfeito bem estar", coloca uma utopia. O que é “perfeito bem estar?" É por acaso possível caracterizar-se a "perfeição"?

Para Farinatti e Ferreira (2006) a concepção da OMS apesar de mostrar uma evolução no conceito de saúde em relação à visão biomédica, ainda não representa a melhor definição devido à dificuldade de se caracterizar precisamente o que constitui um estado completo de bem-estar.

Ao discutir esse tema, Nahas (2006) reafirma que atualmente a tendência é considerar saúde em uma perspectiva holística - enxergando o ser humano como um todo, em todas as suas dimensões biopsicossociais. Recorrendo novamente a Farinatti e Ferreira (2006, p.48), a saúde representa um "estado subjetivo; estaria à mercê dos

\footnotetext{
${ }^{7}$ Embora esse termo ainda possa expressar uma subjetividade, nos permite analisar a saúde em suas diversas abordagens, facilitando a sua compreensão numa perspectiva mais ampla.
} 
valores individuais, que devem ser operacionalizados para uma avaliação subsequente".

Bento ao discutir o aspecto subjetivo da saúde, afirma que:

O entendimento tradicional da saúde não tem hoje peso na balança da Ciência. Para além de um estado biologicamente expresso, a saúde é também entendida como uma categoria fundamentalmente subjetiva como sinônimo para uma qualidade de vida individual que não surge de modo fatalista, mas sim como algo que cada um consegue atingir apenas no confronto ativo com as exigências do universo de sua vida (BENTO, 1991, p. 23,24).

Atualmente, ainda é muito comum a predominância do pensamento biomédico do século XIX quanto à concepção da saúde. Autores como Palma (2001) e Carvalho (2005), discutem essa questão através do viés da culpabilização da pessoa, atribuindo-se a manutenção da saúde prioritariamente como sua responsabilidade - simplesmente adotando um estilo de vida saudável - e não do Estado, que reduziu a sua intervenção social, por exemplo, cortando os investimentos em melhorias de infraestrutura sanitária, moradia, etc. e que passa a enfatizar a conscientização da população a respeito dos cuidados necessários para se ter boa saúde.

Para Buss (2000) a saúde, como um constructo complexo e multifatorial, está relacionada a vários fatores, como as condições de vida proporcionadas à pessoa pela sociedade - infraestrutura sanitária, acesso a tratamentos médicos, renda, dentre outros aspectos - , os fatores ambientais - poluição, acesso a equipamentos de lazer - e comportamentais - estilo de vida. Segundo o mesmo autor:

A nova concepção de saúde importa uma visão afirmativa, que a identifica como bem-estar e qualidade de vida, e não simplesmente como ausência de doença. A saúde deixa de ser um estado estático, biologicamente definido, para ser compreendida como um estado dinâmico, socialmente produzido. Nesse marco, a intervenção visa não apenas diminuir o risco de doenças, mas aumentar as chances de saúde e de vida, acarretando uma intervenção multi e intersetorial sobre os chamados determinantes do processo saúde-enfermidade: eis a essência das políticas públicas saudáveis. Proporcionar saúde significa, além de evitar doenças e prolongar a vida, assegurarem 
meios e situações que ampliem a qualidade da vida "vivida", ou seja, ampliem a capacidade de autonomia e o padrão de bem-estar que, por sua vez, são valores socialmente definidos, importando em valores e escolhas (BUSS, 2000, p.174).

Concordamos com o posicionamento de Buss e, entendemos a saúde como o resultado de uma percepção subjetiva da pessoa, do seu bem estar que envolve uma interação das dimensões física, psíquica, social, espiritual, associada às condições sociais e econômicas que o cercam. Sendo assim, cada pessoa baseando-se em valores culturais e religiosos, avaliará o seu estado de saúde podendo perceber-se saudável ou não - em uma ou mais dimensões acima descritas - , sendo não menos importante oferecer-lhe condições adequadas de vida (MACIEL, 2009).

Retomando a análise do portal do programa em estudo, o subtítulo contém a oração: "Academias da Cidade". Normalmente a palavra academia em nível de senso comum se refere a um lugar onde se realiza alguma prática físico-esportiva, como ginástica, musculação, dança, esportes, dentre outras modalidades, com o objetivo de se melhorar a saúde e a aptidão física/condicionamento físico, portanto, sendo criado um vínculo direto com o título, "saúde".

Já a palavra "cidade", que denota uma área urbanizada, que se diferencia de vilas e outras áreas rurais, também pode ser utilizada para designar uma dada entidade políticoadministrativa urbanizada. Sendo assim, a expressão "Academias da Cidade", apresenta um sentido em promover a saúde à população de áreas urbanas por meio de instalações que permitem a prática de atividades físicas e esportivas.

No segundo subtítulo, é apresentada a oração "Academia da Cidade: saúde e equilíbrio mais próximo do cidadão", trazendo uma associação de reforço entre o objetivo de uma academia, isto é, o que se espera como resultado de quem a frequenta, sobretudo, a saúde; contudo, não se pode desconsiderar que outros benefícios são 
buscados pelas pessoas ao frequentar esse local, como a estética e a socialização. Em seguido aparece uma conjunção aditiva "e", que se usa para unir duas palavras, frases ou orações, somando as ideias já existentes às novas e denotando, assim, uma associação entre saúde e equilíbrio. Segundo o dicionário Michaelis Online, esse último termo por sua vez, é um substantivo masculino que expressa: “1. Física. Estado de um corpo que é atraído ou solicitado por forças cuja resultante é nula. 2. Física. Estado de um corpo que se mantém sobre um apoio, sem se inclinar para nenhum dos lados"; portanto, o que se espera é a que as atividades oferecidas nas academias resulte em um constante estado de saúde. Em seguida, ainda na mesma frase é usado o advérbio ou intensificador "mais", que representa: "1 Designativo de aumento, grandeza ou comparação. 2. Em grau superior, em maior quantidade" (Michaelis Online), assim, expressa a ideia de que a população já tem saúde e que a prefeitura está possibilitando um aumento da mesma às pessoas que frequentam as academias. Por fim, a palavra “cidadão", que é um substantivo masculino, expressando a ideia: "1. Habitante de uma cidade. 2. Indivíduo no gozo dos direitos civis e políticos de um Estado" (Michaelis Online); assim, o discurso transmitido é que a população está tendo os seus direitos garantidos pelo governo ao qual elegeu, em outras palavras, a prefeitura está cumprindo com o seu papel em oferecer saúde à população. Dessa forma, o tema central do discurso é a saúde, tendo como personagem, o cidadão.

Ao analisarmos a primeira oração do texto, “A prática de exercícios físicos tornou-se uma necessidade do ser humano", o exercício físico é entendido em senso comum, como qualquer atividade física que mantém ou aumenta a aptidão física em geral e tem o objetivo de alcançar a saúde e, também como meio de lazer. Em geral, o objetivo da prática de exercícios inclui: o reforço da musculatura e do sistema 
cardiovascular; o aperfeiçoamento das habilidades atléticas; a perda de peso e/ou a manutenção de alguma parte do corpo. Para muitos profissionais da saúde e também em nível de senso comum, exercícios físicos realizados de forma regular estimulam o sistema imunológico e, ajudam a prevenir diversas doenças crônicas não transmissíveis. O verbo "tornar-se" usado nessa frase, denota uma possível mudança de significação e concepção da atividade física para o ser humano. Devido a essas caraterísticas profiláticas atribuídas a essa atividade, talvez, seja por esse motivo que o programa é administrado pela Secretaria Municipal de Saúde e, não pela Secretaria Municipal de Esporte, ou seja, essa atividade é vista como um "medicamento". Assim, associar a atividade física, primeiramente, a uma perspectiva funcionalista - promover saúde e evitar a doença - e, não como uma atividade satisfatória que pode ser vivenciada como uma experiência significativa de lazer, confere a este, uma conotação de ser algo menos importante em relação à saúde.

Em seguida nessa mesma oração, emprega-se a palavra "necessidade", que é um substantivo feminino que expressa: “1. Aquilo que é absolutamente necessário. 2. Indispensabilidade. 3. Inevitabilidade. 4. O que não pode ser de modo diverso do que é. 5. O que tem de ser" (Michaelis Online), atrelada ao ser humano, denotando assim, uma obrigação da prática de exercícios físicos para se ter saúde. Por meio desse discurso ideológico destaca-se uma causalidade linear errônea entre a prática de exercício físico e saúde - que é questionável -, e se pretende culpabilizar a pessoa por possíveis acometimentos patológicos, desviando a responsabilidade do governo em garantir os outros direitos sociais que interferem diretamente na aquisição da saúde.

Na segunda oração do mesmo parágrafo consta: "E a idade não importa quando se deseja ter uma vida saudável, é preciso apenas manter uma disciplina física e 
mental". Inicia-se com a conjunção aditiva “e", estabelecendo relação e dando continuidade à oração anterior, criando uma associação com o fator idade, isto é, ao longo de toda a vida qualquer pessoa deve se exercitar para ter saúde. Para tanto, são usados os verbos "é preciso", com valor imperativo e como algo impositivo, que reforça o substantivo "disciplina", denotando assim, "obediência à autoridade; procedimento correto", aos adjetivos "físico e mental"; em outras palavras, basta a pessoa se submeter às regras apresentadas pelo poder público, subjugando as limitações do corpo e da mente, como por exemplo, a desigualdade social, o cansaço e a preguiça, fatores esses que poderiam atrapalhar alcançar a saúde por meio dos exercícios físicos.

Ainda no mesmo parágrafo consta a oração: "Para quem deseja melhor qualidade de vida sem gastos financeiros, as Academias da Cidade em Belo Horizonte são boas opções”. O discurso apresentado parte do princípio que a pessoa faz uma escolha, “(...) quem deseja (...)”, ou seja, é algo tangível a se obter, como se dependesse somente dele mesmo alcançar esse objetivo. Em seguida está o adjetivo "melhor", que denota: "1. Comparativo irregular de bom, que é mais bom. 2. Superior a outro em bondade ou em qualidade. 3 fam. Menos mal de saúde ou de situação. sm 1. Aquele ou aquilo que é preferível, que tem melhor qualidade que qualquer outra coisa. 2. Aquilo que é sensato ou acertado. Adv. 1. Mais bem. 2. De modo mais perfeito" (MICHAELIS Online). Esse adjetivo precedente ao objeto "qualidade de vida", passa a ideia que a população já tem uma boa qualidade de vida, mas que pode se desenvolver caso pratique alguma atividade física.

Para Guimarães e Martins (2004), o termo "qualidade de vida" foi uma expressão amplamente utilizada a partir da década de 1980, quando se intensificaram as pesquisas relacionadas à questão da pobreza, da exclusão ao consumo, e da 
desigualdade social em todo o planeta. Nahas (2006, p.17) ao discutir essa temática, relata que a mesma "[...] tem emergido como um fator de destaque nas investigações relacionadas á saúde, principalmente ligadas aos cuidados com pacientes de doenças infecciosas graves (AIDS, tuberculose, por exemplo) e crônico-degenerativas" Ainda segundo esse autor:

[...] $\mathrm{Na}$ ausência de definições operacionais amplamente aceitas, é necessário que os investigadores definam claramente qualidade de vida no contexto de seu interesse e identifiquem seus componentes particulares ou domínios incluídos nos instrumentos de medida utilizados (NAHAS, 2006, p. 18).

Fleck et al., (1999) também relatam que embora não haja um consenso a respeito do conceito sobre a qualidade de vida, três aspectos fundamentais referentes a esse constructo foram obtidos através de um grupo de experts de diferentes nações que se reuniram para traçar algumas diretrizes para nortear o estudo da mesma: (1) subjetividade; (2) multidimensionalidade; (3) presença de dimensões positivas (ex. mobilidade) e negativas (ex. dor). Sendo assim, a WHO (1994), definiu a qualidade de vida como "a percepção do indivíduo de sua posição na vida, no contexto da cultura e sistema de valores nos quais ele vive e em relação aos seus objetivos, expectativas, padrões e preocupações".

Para Seidl e Zannon (2004) na área da saúde, o interesse pelo conceito sobre esse tema é relativamente recente e decorre:

Em parte, dos novos paradigmas que têm influenciado as políticas e as práticas do setor nas últimas décadas. Os determinantes e condicionantes do processo saúde-doença são multifatoriais e complexos. Assim, saúde e doença configuram processos compreendidos como um continuum, relacionados aos aspectos econômicos, socioculturais, à experiência pessoal e estilos de vida (SEIDL; ZANNON, 2004, p.580). 
Segundo as autoras, as discussões sobre esse tema atualmente têm enfocado os aspectos da subjetividade e multidimensionalidade. No que concerne à subjetividade, trata-se de considerar a percepção da pessoa sobre o seu estado de saúde e sobre os aspectos não médicos do seu contexto de vida. Em outras palavras, como a pessoa avalia a sua situação pessoal em cada uma dos domínios relacionados à qualidade de vida. $\mathrm{O}$ consenso quanto à multidimensionalidade refere-se ao reconhecimento de que o constructo é composto por diferentes dimensões (física, psicológica, funcional, social, espiritual, ambiental).

Para Seidl e Zannon (2004) a expressão "qualidade de vida" relacionada à saúde e é muito frequente na literatura e tem sido usado com objetivos semelhantes à conceituação mais geral, abordando mais diretamente os aspectos associados às enfermidades ou às intervenções em saúde. Segundo essas mesmas autoras, alguns estudiosos defendem os enfoques mais específicos da qualidade de vida, assinalando que esses podem contribuir para melhor identificar as características relacionadas a um determinado agravo/doença; outros ressaltam que algumas medidas de qualidade de vida relacionada à saúde têm abordagem eminentemente restrita aos sintomas e às disfunções orgânicas, contribuindo pouco para uma visão abrangente dos aspectos não médicos associados ao tema.

Um melhor entendimento da qualidade de vida poderá resultar em mudanças nas práticas assistenciais e na consolidação de novos paradigmas do processo saúde-doença, o que pode ser de grande valia para a superação de modelos de atendimento focados somente na medicalização, e que negligenciam aspectos como os socioeconômicos, psicológicos e culturais, importantes nas ações de promoção, prevenção, tratamento e reabilitação em saúde. Assim, sendo qualidade de vida um constructo eminentemente 
interdisciplinar, a contribuição de diferentes áreas do conhecimento pode ser de fato valiosa e mesmo indispensável (SEIDL; ZANNON, 2004).

Em termos da ACD pode-se dizer que a "qualidade de vida" configura-se como ideologia dominante no discurso médico e relacionado com a saúde na atualidade e, identificamos o que na concepção de Fairclough (2001), é uma "tecnologização" onde discursos pertencentes à dada esfera estão sendo sistematicamente simuladas dentro de outras áreas. Em outras palavras, transfere-se o discurso médico para os veículos populares de transmissão, ou vice versa, em prol da adesão de um dado público-alvo. Nesses termos, a "qualidade de vida" se situa no âmbito das práticas sociais, apontado por Fairclough, mas a forma de se atingir essa prática social, é a utilização de palavras e expressões linguísticas contidas no discurso enquanto texto.

Ainda relacionado à mesma sentença em questão estudada, "Para quem deseja melhor qualidade de vida sem gastos financeiros, as Academias da Cidade em Belo Horizonte são boas opções", há a oração “[...] sem gastos financeiros [...]" e pode-se entender que há uma associação entre a melhoria da qualidade de vida com algum gasto financeiro, mas que o governo está ofertando essa possibilidade ao disponibilizar a população tal programa, sendo sua principal usuária. Outra conotação possível a ser feita em relação ao fator financeiro é que o poder público por meio dessa proposta visa alcançar, sobretudo, a população de baixo nível socioenômico, pois essa, não teria condições de arcar com despesas para se conseguir uma melhor qualidade de vida.

Esse discurso pode também representar que a população de baixo nível socioenômico é responsável em parte pelos altos índices de adoecimento por DCNT na sociedade - pois ao não ter condições financeiras de melhorar a sua qualidade de vida, 
pela prática de exercícios físicos -, o poder público disponibiliza programas específicos à mesma.

Finalizando o primeiro parágrafo no texto, encontra-se a sentença: "Desde 2006, a Prefeitura de Belo Horizonte coloca em funcionamento essa rede de academias, desenvolvida pela Secretaria Municipal da Saúde”. Ao se iniciar a sentença com a preposição "desde", que denota uma temporalidade que estabelece uma relação entre o passado e o futuro como se há muito tempo houvesse esse programa; contudo, sendo algo recente, apenas nove anos. É reforçada a ideia de que há uma "rede", isto é, há diversas instalações em várias localidades na cidade que atende a demanda da população para a prática dos exercícios físicos. Essa conotação dada transparece uma ação direcionada, sobretudo, à obtenção da saúde, almejando um objetivo funcionalista, isto é, evitar e/o controlar o acometimento de doenças e, também à promoção da saúde. Todavia, em momento algum faz menção aos benefícios que o lazer proporciona, como a socialização, um tempo dedicado a si mesmo, a vivência de atividades culturais diferenciadas etc.

O segundo parágrafo do texto inicia com a sentença "Promover saúde e contribuir para melhoria da qualidade de vida são os principais objetivos da Academia da Cidade". Ao analisarmos a proposta da promoção da saúde, as principais diretrizes desse movimento surgiram a partir de uma conferência promovida pela OMS na cidade de Ottawa no Canadá (1986), na qual foi publicado um documento que ficou conhecido como Carta de Ottawa, definindo a promoção da saúde como o processo de capacitação da comunidade para atuar na melhoria da sua qualidade de vida e saúde, incluindo uma maior participação no controle deste processo. 
Os princípios apresentados por esse documento estipulam a promoção da saúde associados a um conjunto de valores como: qualidade de vida, bem-estar, solidariedade, equidade, democracia, cidadania, desenvolvimento, participação e parceria, entre outros. Para o alcance desses objetivos, a OMS estipulou cinco áreas principais de intervenção: 1) Elaboração e implementação de políticas públicas saudáveis - A primeira diretriz diz respeito ao desenvolvimento de políticas públicas que combinem diversas abordagens complementares, incluindo a legislação, as medidas fiscais, os impostos e as mudanças organizacionais. (Uma política de promoção da saúde exige a identificação de obstáculos e de fatores facilitadores para a adoção de ações em Inter setoriais visando a saúde; 2) Criação de ambientes favoráveis à saúde - consiste na proteção de ambientes naturais ou criados pelo homem e a conservação dos recursos naturais devem ser considerados em conta em qualquer estratégia de promoção da saúde.; 3) Reforço da ação comunitária - desenvolve-se através da intervenção concreta e efetiva na comunidade, estabelecendo prioridades, tomando decisões, planejando estratégias e implementando-as com vista a atingir a melhor saúde; 4) Desenvolvimento de habilidades pessoais - pressupõe o desenvolvimento pessoal e social, através da melhoria da informação, educação para a saúde e reforço das competências que habilitem para uma vida saudável. Deste modo, as populações ficam mais habilitadas para controlar a sua saúde e o ambiente e fazer opções conducentes à saúde; 5) Reorientação do sistema de saúde - a responsabilidade da promoção da saúde deve ser partilhada com os indivíduos, grupos comunitários, profissionais e instituições de saúde, e com os governos (federal, estadual e municipal). Todos devem trabalhar em conjunto pela criação de um sistema de cuidados de saúde que contribua para a obtenção da saúde. 
Para Buss (2000) esse tema vem sendo interpretado de um lado como reação à acentuada medicalização das pessoas pela medicina, e, de outro, como uma resposta setorial articuladora de diversos recursos técnicos e posições ideológicas:

O que, entretanto, vem caracterizar a promoção da saúde, modernamente, é a constatação do papel protagonista dos determinantes gerais sobre as condições de saúde, em torno da qual se reúnem os conceitos do segundo grupo. Este se sustenta no entendimento que a saúde é produto de um amplo espectro de fatores relacionados com a qualidade de vida, [...]. Suas atividades estariam, então, mais voltadas ao coletivo de indivíduos e ao ambiente, compreendido num sentido amplo, de ambiente físico, social, político, econômico e cultural, através de políticas públicas e de condições favoráveis ao desenvolvimento da saúde (as escolhas saudáveis serão as mais fáceis) e do reforço (empowerment) da capacidade dos indivíduos e das comunidades (BUSS, 2000, p.167).

Os determinantes da saúde referidos por Buss (2000), são baseados no modelo canadense de saúde em quatro amplos componentes: 1) biologia humana - consiste dos aspectos hereditários que interferem na saúde, 2) ambiente - deve-se levar em consideração os fatores relacionados à poluição em suas diferentes formas, bem como à infraestrutura sanitária e áreas verdes, 3) estilo de vida - relacionados nos comportamentos adquiridos pela população, por exemplo, alimentação saudável, prática de atividades física, controle dos fatores estressores etc.; e 4) organização da assistência à saúde - ações vinculadas à saúde em suas diferentes modalidades, primária, secundária e terciária, sobretudo, na primeira que está relacionado aos aspectos da promoção da saúde; dentro dos quais se distribuem inúmeros fatores que a influenciam. Sendo assim, para se alcançar os objetivos propostos por essas diretrizes, a saúde deve ser vista de forma multiprofissional e intersetorial, e não de maneira simplista, além de requerer a viabilização de políticas públicas que contribuam para a melhoria da mesma.

O programa em questão segue essas diretrizes propostas, sendo o resultado de uma política pública da saúde que prevê a disponibilização de polos que permitam a 
prática de atividades físicas e outras atividades pedagógicas como palestras para promover a educação para a saúde, orientadas por profissionais dessa área - Educação Física, Fisioterapeuta, Nutricionistas, Farmacêuticos etc. Essas ações também podem estar atreladas à intervenção da Estratégia da Saúde da Família que atuam nessas comunidades.

Contudo, esse programa deveria estar associado com as melhorias dos determinantes da saúde que o governo é responsável, como uma melhor urbanização mobilidade e arborização, redução dos índices de poluição, dentre outros aspectos -, a eliminação das falhas na infraestrutura sanitária básica, solução da precarização do atendimento médico público - consultas, realização de exames e tratamentos diversos -, bem como, na melhoria dos níveis de qualidade da educação e políticas de emprego e renda realmente eficazes. Portanto, o que se percebe de maneira ampla em todo o Brasil, são ações secundárias, como a proposta por essa modalidade de programa, que foca na mudança do estilo de vida da população, ao invés de investimentos adequados concomitantes aos outros fatores determinantes da saúde.

Em seguida à frase em análise, apresenta-se que: "Antes do início das aulas, os usuários passam por uma avaliação física com um Profissional de Educação Física para que o mesmo seja direcionado ao treinamento mais adequado, pois as atividades são realizadas de acordo com a necessidade e condições físicas de cada pessoa."; essa afirmativa visa denotar uma profissionalização do programa, caracterizada pela intervenção de um profissional que lida diretamente na orientação da prática da atividade física com caráter preventivo, de forma a dar credibilidade que o mesmo segue os princípios científicos, destacado pela necessidade da realização de procedimentos diagnósticos, avaliação física, para posteriormente se fazer a prescrição do treinamento 
adequado. O programa oferece diferentes tipos de modalidades, como descrito pelo anúncio: "As atividades realizadas visam a melhora do condicionamento cardiorrespiratório, consciência corporal, flexibilidade, força e coordenação motora geral, através dos conteúdos da Educação Física, como ginásticas, danças, jogos, esportes, lutas e caminhada orientada", que serão recomendadas individualmente, pelos profissionais que fazem a avaliação. Estes, por sua vez, seguirão os princípios funcionalistas apregoados pela epidemiologia da atividade física para a prescrição do treinamento a ser realizada pela pessoa.

Contudo, encontra-se contradição no discurso, pois as atividades não são conduzidas de forma individualizada, "[...] de acordo com a necessidade e condições físicas de cada pessoa [...]", mas em aulas coletivas, tendo um acompanhamento subjetivo do esforço do aluno. Normalmente nesses tipos de aula, ocorre um planejamento considerando o coletivo e o desenvolvimento de determinadas capacidades físicas, e não as singularidades pessoais; embora, o aluno seja orientado a fazer as atividades de maneira confortável, conforme a sua capacidade. Portanto, descaracteriza a afirmativa da especificidade do treinamento realizado.

Seguindo o texto apresentado no portal do programa, é apontada a prescrição da frequência e duração das atividades a serem feitas pelos usuários no programa, seguindo novamente os princípios biomédicos de um tratamento, como se a atividade física fosse uma medicação: "Cada usuário pode utilizar a academia por um período de uma hora, três vezes durante a semana". Essa afirmativa apresenta uma conotação de permissão e, também a coerência às atuais recomendações dadas pela OMS em que as pessoas adultas precisam realizar, pelo menos, 150 minutos de atividade física semanalmente para obter benefícios à saúde. Desta forma, mais uma vez caracteriza-se o aspecto 
predominantemente profilático dado ao programa, ao invés de ser entendido também como um momento de lazer e local de socialização das pessoas.

Para legitimar essa recomendação, o texto traz o depoimento da coordenadora do projeto, Vera Guimarães, que também é uma profissional de Educação Física ${ }^{8}$, isto é, de uma especialista: "Incentivamos para que as pessoas pratiquem o que aprenderam em outras situações do dia-a-dia, como durante a arrumação da casa e a caminhada"; essa fala denota que a realização de tarefas domésticas, também entendidas como sendo uma atividade física, podem, assim, contribuir para a melhoria da saúde, complementando o que é realizado no programa. Novamente esse discurso se baseia nas diretrizes da OMS que entende essas tarefas corriqueiras, auxiliam na obtenção da aptidão física relacionada à saúde. Segundo Nahas (2006) a aptidão física pode ser subdividida em duas vertentes: a relacionada à saúde e à performance. Segundo esse autor, a primeira contempla atributos biológicos - força e resistência muscular, flexibilidade, capacidade aeróbica, controle ponderal - que oferecem alguma proteção ao aparecimento de distúrbios orgânicos provocados pelo estilo de vida sedentário. Quanto à performance, ela envolve uma série de componentes relacionados ao desempenho esportivo ou laboral, tais como: a agilidade, o equilíbrio, a coordenação, a potência e as velocidades de deslocamento e de reação muscular. Esse aspecto é reforçado novamente pelo texto e pela fala da coordenadora do programa: "O objetivo é proporcionar mais qualidade de vida para a pessoa e o que vale 'não é ter um corpo sarado, mas um corpo saudável', completa".

Nessa sentença, a coordenadora retorna a reforçar um dos objetivos do programa já apresentado no início do texto "promover a qualidade de vida", contudo, os

\footnotetext{
${ }^{8}$ Informação obtida por meio de contato telefônico com a mesma.
} 
exercícios praticados no programa tem uma finalidade diferente aos executados na perspectiva da aptidão física relacionada ao desempenho, o que por sua vez, não irá promover alterações morfológicas, isto é, aumento da hipertrofia muscular, ou como dito em senso comum, um “corpo sarado”, mas, "um corpo saudável”, capaz de prevenir as chances do acometimento de uma doença, ou o seu controle, ou mesmo de tratá-la, podendo inclusive curá-la; outra possibilidade seria a melhora da saúde.

Essa diferenciação feita quanto ao "corpo sarado" e "corpo saudável”, tem o intuito de desfazer o estereótipo das academias tradicionais, privadas, que são normalmente locais para pessoas jovens, magras com o intuito de se trabalhar o aspecto estético corporal, isto é, de ganhar massa e definir a musculatura. Pois essa é a imagem apresentada pela mídia ao destacar os "corpos perfeitos" de modelos e personalidades. A proposta dessa declaração é desfazer a imagem de um ambiente semelhante às academias tradicionais. Assim, o discurso apresentado, pretende criar a expectativa de outra "atmosfera", mais "suave", sem o estereótipo inibidor encontrado naquelas academias, incentivando as "pessoas simples" que não têm pretensão de adquirir um "corpo sarado", mas pelo contrário, apresenta um "corpo arrendado", acima do peso, com limitações físicas, um "corpo enferrujado" e "constrangido" pela propaganda midiática, a se inscreverem no programa.

No penúltimo parágrafo na descrição do programa, é apresentada a distribuição das academias nas regionais da cidade e os diferentes horários de atendimento à população - em seguida ao texto, segue uma listagem com a localização das mesmas de acordo com as regionais e bairros, os telefones para contato e horário de funcionamento -, bem como a capacidade média de atendimento de cada unidade, 400 pessoas, 
ressaltando que diversas pessoas podem frequentar o local, ou seja, de diferentes faixas etárias, sexo e limitações físicas.

Em seguida é destacado o caráter "gratuito", denotando que não há nenhum impedimento às pessoas que não têm condições financeiras para pagar uma academia “comercial” e, que, portanto, não há empecilhos para a não participação no programa disponibilizado. No mesmo parágrafo, é destacado um público-alvo e a facilidade de participar do programa, basta realizar uma avaliação física feita por profisssional habilitado e especialista em atividade física: “[...] preferencialmente acima de 18 anos, pode participar das atividades, basta preencher o cadastro e fazer a avaliação física com o professor na academia mais próxima". Essa frase passa a ideia de simplicidade de adesão, o que talvez motivasse as pessoas o procurar. Contudo, não considera as limitações pessoais para aderirem ao programa, como, por exemplo, oferecer diferentes horários à população, pois as atividades se concentram especialmente na parte da manhã, com alguns poucos polos com atividades nos períodos vespertino e/ou noturno.

\section{Considerações Finais}

A prática social analisada neste trabalho foi o discurso da atividade física como fator de promoção da saúde e qualidade de vida. Percebe-se notoriamente o discurso ideológico do poder público em cumprir a sua responsabilidade social para com a população ao implantar alguns polos de academias gratuitas e, com orientação profissional qualificada.

O poder público assumindo as diretrizes da Saúde Pública, tem adotado uma perspectiva positivista-funcionalista ao desenvolver tais programas. Essa abordagem se apropria de uma visão reducionista, mecanicista e fragmentada sobre a concepção do ser 
humano, refletindo no entendimento do que seria a saúde. Essa visão tem como diretriz a dicotomia biológica entre saúde-doença, por meio da abordagem anátomofisiopatológica dos órgãos e tecidos do corpo humano.

Contudo, embora ainda que essa perspectiva seja hegemônica, identificam-se esforços no meio acadêmico e também no campo profissional nos últimos anos para superar esse viés, buscando discutir os aspectos valorativos e éticos do ser no mundo, isto é, na promoção da vida e não apenas da saúde.

Mas, de qual concepção de saúde está se falando? A sua discussão crítica procura extrapolar da visão reducionista do processo saúde-doença, na perspectiva da medicina biologicista, mas, busca compreendê-la de forma multifatorial e complexa.

A saúde está relacionada a vários fatores, como as condições de vida proporcionadas à pessoa pela sociedade, como, por exemplo, a infraestrutura sanitária, poluição, acesso à saúde, renda, escolaridade e, também a fatores comportamentais relacionados ao estilo de vida.

Não menos importante, é a oferta de acesso a espaços e equipamentos de lazer, bem como a intervenção dos profissionais que atuarão nessa área. Assim, o desenvolvimento dessas atividades pautadas em uma perspectiva de um lazer consciente, democrático e satisfatória, isto é, não funcionalista, poderá contribuir sim, para a melhoria da qualidade de vida da população. Entende-se também que essa intervenção não deveria ser simplesmente padronizada e sistematizada pela ciência e pelo mercado, seguindo um modismo, ou proporcionando uma mera reprodução de movimentos estereotipados.

Contudo, o intuito ao realizar essa análise não é desmerecer a iniciativa do poder público que cumpre com o seu papel social; pelo contrário, deveria ampliar essas ações, 
democratizando o acesso ao lazer como direito social; nem mesmo aos profissionais que atuam no programa, seguindo um viés positivista. Todavia, não podemos deixar de tecer críticas à uma concepção hegemônica de tais ações, que muitas vezes desconsidera a necessidade da implementação concomitante de outras iniciativas para promover a equidade social, o que realmente possibilitaria o pleno desenvolvimento da promoção da saúde e da qualidade de vida da população.

\section{REFERÊNCIAS}

ALBINO, B. S.; HAMMES, P. D.; VAZ, A. F. Sobre o bem-estar na Revista Boa Forma: Corpo, lazer, normalização. Educ. Real, Porto Alegre, v. 36, n. 2, p. 569-585, maio/ago. 2011. Disponível em: http://www.redalyc.org/html/3172/317227057006/index.html. Acesso em: 14 jan. 2016.

ANDRADE, M. V. "Projetos sociais" de esporte e lazer: Reflexões, inquietações, sugestões; em: https:quadernsanimacio.net; $\mathrm{n}^{\circ}$ 7; enero de 2008. Disponível em: http:/quadernsanimacio.net/ANTERIORES/siete/VICTOR\%20ANDRADE.pdf. Acesso em: 14 jan. 2016.

AREIAS, K. T. V.; BORGES, C. N. F. As políticas públicas de lazer na Mediação entre estado e sociedade: Possibilidades e limitações. Rev. Bras. Ciênc. Esporte, Florianópolis, v. 33, n. 3, p. 573-588, jul./set. 2011. Disponível em: http://revista.cbce.org.br/index.php/RBCE/article/view/662/678. Acesso em: 14 jan. 2016.

BACHELADENSKI, M. S.; MATIELLO JÚNIOR, E. Contribuições do campo crítico do lazer para a promoção da saúde. Ciência \& Saúde Coletiva, v. 15, n. 5, p. 25692579, 2010. Disponível em: http://www.scielo.br/pdf/csc/v15n5/v15n5a31.pdf. Acesso em: 14 jan. 2016.

BENTO, J. Desporto, saúde e vida: em defesa do desporto. Lisboa: Livros Horizonte. 1991.

BUSS, P. M. Promoção da saúde e qualidade de vida. Revista Ciência e Saúde Coletiva. Rio de Janeiro, v.5, n.1, p. 163-177, 2000. Disponível em: http://lms.ead1.com.br/upload/biblioteca/curso_11528/94251519066001152861548.pdf. Acesso em: 14 jan. 2016.

CARVALHO, Y. M. Lazer e saúde. Brasília: SESI/DN. 2005. 
CARVALHO, Y. M. Formação profissional em políticas públicas de lazer com enfoque na saúde. In: MARCELLINO, N. C (Org.). Formação e desenvolvimento de pessoal em lazer e esporte. Campinas: Papirus, 2003. p. 121-135.

FAIRCLOUGH, N. Discurso e Mudança Social. Brasília: Editora da UnB. 2001.

Discourse and Social Change. Cambridge: Polity, 1994.

Media Discourse. London: Hodder Arnold, 1995.

FARINATTI, P.T.V.; FERREIRA, M.S. Saúde, promoção da saúde e educação física: Conceitos, princípios e aplicações. Rio de Janeiro: Editora UERJ. 2006.

FLAUSINO, M.S.; MASCARENHAS, F. O direito ao esporte e lazer: apontamentos críticos à sua mistificação. Licere, Belo Horizonte, v.15, n.2, jun/2012. Disponível em: http://www.anima.eefd.ufrj.br/licere/pdf/licereV15N02_a5.pdf. Acesso em: 14 jan. 2016.

FLECK, M. P. A. et al. Desenvolvimento da versão em português do instrumento de avaliação de qualidade de vida da OMS (WHOQOL-100). Revista Brasileira de Psiquiatria, 21(1), 1999. Disponível em: http://www.revistas.usp.br/rsp/article/viewFile/25001/26829. Acesso em: 23 out. 2014.

GUEDES, D.P. Atuação do professor de educação física no campo da saúde. In: LEBRE, E.; BENTO, J. (Org.). Professor de Educação Física: Ofícios da Profissão. Porto, Portugal: Universidade do Porto. 2004.

GUIMARÃES, E.; MARTINS, V. L. A. B. Qualidade de vida. In: GOMES, C.L. (Org.). Dicionário crítico do lazer. São Paulo: Autêntica, 2004.

HALLAL, P. C.; KNUTH, A. G. Epidemiologia da atividade física e a aproximação necessária com as pesquisas qualitativas. Revista Brasileira de Ciências do Esporte, v. 33 , n. 1, p. 181-192, jan./mar. 2011. Disponível em: http://www.scielo.br/pdf/rbce/v33n1/a12v33n1.pdf. Acesso em: 14 jan. 2016.

ISAYAMA, H. F. Reflexões sobre os conteúdos físico-esportivos e as vivências de Lazer. In: Nelson Carvalho Marcellino. (Org.). Lazer e Cultura. Campinas: Alínea, 2007, v. 1, p. 31-46.

MACIEL, M. G.; DIAS, C.; SILVA, L. P. Lazer e atividade física no Brasil. O profissional de educação física na área da saúde. [recurso eletrônico]. In: NOCE, Franco et al. (Coord.). Belo Horizonte,2014. Disponível em: http://www.eeffto.ufmg.br/eeffto/documento/incoming/docs/prof-ed-saude-livro.pdf. Acesso em: 10 ago. 2014.

Análise comparativa da intenção de mudança do comportamento em adolescentes para a prática de atividades físicas regulares de lazer. 2009. Dissertação (Mestrado). Universidade Federal de Minas Gerais, Escola de Educação Física, Fisioterapia e Terapia Ocupacional, 2009. 
MALTA, D. C.; CASTRO, A. M., et al. A Política Nacional de Promoção da Saúde e a agenda da atividade física no contexto do SUS. Epidemiologia do Serviço de Saúde, Brasília, v. 18, n. 1, p. 79-86, jan-mar. 2009. Disponível em: http://scielo.iec.pa.gov.br/pdf/ess/v18n1/v18n1a08.pdf. Acesso em: 14 jan. 2016.

.; MORAIS NETO, O. L.; SILVA JUNIOR, J. B. Apresentação do plano de ações estratégicas para o enfrentamento das doenças crônicas não transmissíveis no Brasil, 2011 a 2022. Epidemiologia do Serviço de Saúde, Brasília, v. 20, n. 4, p. 425 438, out-dez. 2011. Disponível em: http://scielo.iec.pa.gov.br/pdf/ess/v20n4/v20n4a02.pdf. Acesso em: 14 jan. 2016.

MARCELlinO, N. C. Políticas públicas de lazer - formação e desenvolvimento de pessoal: os casos de Campinas e Piracicaba-SP. Curitiba: OPUS, 2007.

Lazer e educação. Campinas: Papirus, 1987.

MICHAELIS. Dicionário online. https://michaelis.uol.com.br/.

NAHAS, M. V. Atividade física, saúde e qualidade de vida: Conceitos e sugestões para um estilo de vida saudável. (4. ed. rev. e atual.). Londrina: Midiograf, 284 p. 2006.

PALMA, A. Educação Física, corpo e saúde: uma reflexão sobre outros "modos de olhar". Revista Brasileira de Ciências do Esporte, v. 22, n.2, p.23-39, jan. 2001. Disponível em: http://revista.cbce.org.br/index.php/RBCE/article/view/410/384. Acesso em: 14 jan. 2016.

PIMENTEL, G. G. A. O passivo do lazer ativo. Movimento, Porto Alegre. v. 18, n. 03, p. 299-316, jul/jset de 2012. Disponível em: http://www.seer.ufrgs.br/index.php/Movimento/article/view/22059/21257. Acesso em: 14 jan. 2016.

RODRIGUES JUNIOR, A. S. Análise crítica do discurso: modismo, teoria ou método? Belo Horizonte: RBLA, v. 9, n. 1, p. 99-132. 2009. Disponível em: http://www.scielo.br/pdf/rbla/v9n1/06.pdf. Acesso em: 14 jan. 2016.

SEIDL, E. M. F.; ZANNON, C. M. A. L. C. Qualidade de vida e saúde: aspectos conceituais e metodológicos. Caderno de Saúde Pública, Rio de Janeiro, v. 20, n. 2, p. 580-588, mar-abr, 2004. Disponível em: http://www.scielo.br/pdf/csp/v20n2/27.pdf. Acesso em: 14 jan. 2016.

SERGE, M.; FERRAZ, F. C. O conceito de saúde. Revista de Saúde Pública. v. 31, n. 5, p. 538-542,. 1997.

SOARES, L.A. Discurso e Representação Masculina em Peças Publicitárias da Revista Men's Health. Revista da ABRALIN, v. 10, n. 1, p. 33-59, 2011. Disponível em: http://www.abralin.org/site/data/uploads/revistas/2011-vol-10-n-1/leonardo-antoniosoares.pdf. Acesso em: 12 nov 2014. 
SUASSUNA, D. M. F.; AZEVEDO, A. A (Org.). Política e lazer: interfaces e perspectivas. Brasília: Thesaurus, 2007. 240 p. Disponível em: http://www2.esporte.gov.br/arquivos/snelis/esporteLazer/cedes/politicasPublicas/politic aLazerInterfacesPerspectivasUNB.pdf. Acesso em: 14 jan. 2016.

WORLD HEALTH ORGANIZATION (WHO). Global strategy on diet, physical activity and health. Geneva, 2004. Disponível em: http://www.who.int/dietphysicalactivity/strategy/eb11344/strategy_english_web.pdf. Acesso em: 04 mar 2010.

\section{Endereço dos Autores:}

Marcos Gonçalves Maciel

Universidade do Estado de Minas Gerais. Av. São Paulo, 3.996, Vila Rosário, Ibirité - MG - 32.400-000

Endereço Eletrônico: marcosgmaciel@hotmail.com

Leonardo Antônio Soares

Universidade do Estado de Minas Gerais.

Av. São Paulo, 3.996, Vila Rosário,

Ibirité - MG - 32.400-000

Endereço Eletrônico: leons@rocketmail.com 